\title{
IMPLEMENTASI STRUKTUR DATA TREE PADA GAME PACMAN DENGAN C
}

\author{
Hanhan Septian ${ }^{1}$, Ida Suhartini ${ }^{2}$, Irfan Pertrio N ${ }^{3}$, Lubban Ahsanul Jihad ${ }^{4}$, Nur Lia ${ }^{5}$, Toriq Fadilah A $^{6}$ \\ Politeknik Negeri Bandung \\ J1. Gegerkalong Hilir, Ciwaruga, Kec. Parongpong, Kabupaten Bandung Barat, Jawa Barat 40559 \\ Email : hanhan.septian.tif20@polban.ac.id ${ }^{1}$, ida@jtk.polban.ac.id ${ }^{2}$, irfan.pertrio.tif20@ polban.ac.id ${ }^{3}$, \\ lubban.ahsanul.tif20@polban.ac.id ${ }^{4}$, nur.lia.tif20@polban.ac.id ${ }^{5}$, thoriq.fadhillah.tif20@polban.ac.id ${ }^{6}$
}

\begin{abstract}
ABSTRAK
Pac-Man merupakan sebuah permainan yang bisa dimainkan oleh seorang player dengan karakter didalamnya yang biasanya berbentuk bulan dan berwarna kuning. Selain itu, Pac-man mempunyai musuh yang digambarkan seperti hantu / ghost dengan aturan yang telah ditentukan. Karakter dari permainan Pacman dan jalur permainan dimodelkan menggunakan tree atau pohon. Struktur tree adalah struktur yang mengandung aspek hirarki yang dibentuk melalui pengelompokkan elemen atau node dalam tingkatan tertentu.
\end{abstract}

Kata kunci: Program, Permainan Pacman, Struktur data tree, Bahasa C

\begin{abstract}
Pac-Man is a game that can be played by a player with characters in it which are usually moon-shaped and yellow. In addition, Pac-man has enemies who are described as ghosts / ghosts with predetermined rules. The characters from the Pacman game and the game path are modeled using trees. The tree structure is a structure that contains a hierarchical aspect that is formed through grouping elements or nodes in a certain level.
\end{abstract}

Keywords: Program, Pacman Game, Data tree structure, C language

\section{PENDAHULUAN}

\subsection{Latar Belakang}

Pac-Man adalah sebuah permainan arkade yang dikembangkan Namco dan diterbitkan Midway; dirilis di Jepang pada 22 Mei 1980. Awalnya dirilis di arkade saja, Pac-Man yang masih populer hingga kini telah dirilis pula dalam platform lainnya seperti Game Boy dan SNES. Perancang permainan ini adalah Toru Iwatani, yang merupakan karyawan Namco.

Pemain harus mengontrol tokoh berwarna kuning bernama Pac-Man dan membawanya mengelilingi lorong berlika-liku sambil "memakan" titik-titik kecil dan benda-benda khusus lainnya. Pada saat yang sama, terdapat empat "hantu" yang berkeliling di lorong tersebut yang bertugas menangkap Pac-Man. Sang pemain dapat menyelesaikan satu level (tingkat) jika berhasil memakan seluruh titik dan benda khusus. Secara teori, permainan dapat terus berlanjut tanpa batasan tingkat, namun tingkat ke-256 memiliki bug yang menyebabkan gambar di layar tidak beraturan dan karena itu Pac-Man tidak dapat terus dimainkan melewati tingkat tersebut.

Pac-Man kini dianggap sebagai salah satu permainan video klasik serta merupakan salah satu ikon tahun 1980-an. Salah satu alasan kesuksesannya adalah bentuk permainannya yang dapat digemari baik pria maupun wanita dibandingkan dengan permainan arkade lainnya sebelum Pac-Man seperti Space Invaders dan Defender yang merupakan permainan tembak-tembakan. 


\subsection{Tujuan Penelitian}

Adapun yang menjadi tujuan dari penelitian ini adalah untuk mengembangkan program permainan Pacman yang sudah ada dengan menggunakan struktur data tree yang diterapkan dalam program C.

\section{KAJIAN PUSTAKA}

\subsection{Struktur Data Tree}

Karakter dari permainan Pacman dan jalur permainan dimodelkan menggunakan tree atau pohon. Struktur tree adalah struktur yang mengandung aspek hirarki yang dibentuk melalui pengelompokkan elemen atau node dalam tingkatan tertentu.

Terdapat macam-macam jenis tree beserta cabang ilmu lainnya yang berkaitan dengan jenis-jenis tree tersebut. Salah satunya adalah binary tree. Jenis tree tersebut identik dengan ciri parent yang pasti hanya memiliki dua anak.

\subsection{AVL Tree}

Guna meminimalisir kompleksitas waktu dalam proses pengolahan data pada tree yang diterapkan, maka diperlukan metode otomatisasi penyeimbangan tinggi pohon. Metode ini disebut AVL tree yang dimanfaatkan pada pohon biner (binary tree). Waktu yang dibutuhkan dalam pencarian data, dijamin bernilai konstan apabila metode ini diterapkan.

Penyeimbangan tinggi pohon dilakukan dengan proses rotasi. Proses rotasi tersebut menyebabkan adanya pergeseran pointer yang menunjuk root pada tree serta terbentuknya jalur node baru. Jalur node baru tersebut pastinya memiliki nilai seimbang ketika dihitung oleh otomatisasi $A V L$.

\section{METODE PENELITIAN}

Berdasarkan metode yang telah dipaparkan serta penggambaran program yang akan dikembangkan, analisis terhadap implementasi pun dilakukan. Struktur data tree beserta AVL tree hanya dapat diimplementasikan pada karakter permainan yaitu Pacman.

Karakter permainan Pacman digambarkan memiliki bentuk bulat yang biasanya berwarna kuning dengan musuh yang digambarkan seperti ghost.

Implementasi binary tree dirasa akan lebih efisien karena nantinya dapat diterapkan $A V L$ yang mempercepat proses pengolahan data pada tree. Sehingga program dapat bekerja secara lebih optimal.

\subsection{Metode Perancangan}

Dalam pembuatan permainan Pacman tentunya dibutuhkan sebuah tahapan perancangan agar permainan yang dibuat sesuai dengan yang diinginkan. Secara garis besar terbagi menjadi beberapa tahapan berikut :

1. Tahap Riset dan Penyusunan Konsep Dasar

Pada tahap ini konsep dasar, tema, teknologi, media (platform), serta berbagai batasan lain dirumuskan. Tahapan riset ini menjadi sebuah tahapan penting, berbagai elemen dasar dari permainan disusun di sini.

2. Perumusan Mekanika Permainan

Pada tahap ini tim pengembang merumuskan mekanika permainan. Mekanika permainan merupakan pola, aturan, atau mekanisme yang mengatur bagaimana proses interaksi pemain dengan permainan yang dibuat.

3. Penyusunan Asset dan Level Design

Tahapan ini fokus pada penyusunan konsep dari semua karakter serta asset termasuk suara/musik yang diperlukan. Pada tahap ini pula tim pengembang melakukan pengelompokan tingkat kesulitan serta berbagai asset yang tepat sehingga permainan dapat menghadirkan pengalaman bermain yang optimal.

4. Development

Pada tahap ini seluruh konsep yang sebelumnya telah tersusun mulai dikembangkan secara penuh serta semua elemen mulai dipadukan.

5. $\quad$ Testing

Pada tahap ini berfokus untuk mengetahui apakah semua komponen utama permainan mampu memberikan pengalaman bermain yang diharapkan serta dapat diketahui apakah ada masalah teknis yang belum terdeteksi sebelumnya. 


\subsection{Perancangan Modul}

Dalam pembuatan program, tentu saja diperlukan beberapa modul yang mana dalam modul-modul tersebut berisi logika yang menjadi dasar berjalannya program. Modul-modul utama yang akan diimplementasikan sebagai berikut :

1. Modul dengan fungsi umum yaitu menampilkan. Misalnya menampilkan arena permainan, papan jumlah perolehan skor dan nyawa karakter, menampilkan karakter Pacman, dan objek makanan karakter Pacman.

2. Modul dengan fungsi yang bersangkutan dengan logika dalam pemodelan karakter Pacman dengan struktur data tree.

3. Modul dengan fungsi untuk mengatur gerakan karakter. Modul ini memiliki ciri umum pada penamaan modulnya, yaitu terdapat kata yang merujuk ke macam-macam arah, misalnya kanan (right) dan kiri (left).

\subsection{Perancangan Tampilan}

Antarmuka dari program menjadi salah satu unsur penting, guna menarik minat pengguna serta kenyamanan visual. Antarmuka yang menjadi output dari program permainan Pacman ini dirancang untuk menampilkan,

1. Karakter Pacman, yang berbentuk bulat berwarna kuning

2. Objek makanan karakter, terbagi menjadi makanan utama, dan makanan bonus.

3. Latar belakang/background,

4. Button, terdiri dari button play game, credits, highscore dan button exit,

5. Area permainan dengan tiga pilihan map yang dirancang berbeda.

\section{IMPLEMENTASI SISTEM}

4.1 Implementasi Modul

Modul-modul yang diimplementasikan pada pembuatan permainan Pacman sebagai berikut :

Tabel 1. Implementasi Modul dalam Permainan Pacman

\begin{tabular}{|l|l|l|}
\hline No & Nama Modul & Deskripsi \\
\hline 1. & iniBagianMenu & $\begin{array}{l}\text { Modul ini berfungsi untuk menampilkan } \\
\text { tampilan loading pada game }\end{array}$ \\
\hline 2. & sprite *sprite_create & $\begin{array}{l}\text { Modul ini bertujuan mengalokasikan data pada } \\
\text { maps agar gambar dapat terbaca }\end{array}$ \\
\hline 3. & Makelist & Untuk membuat list maps \\
\hline 4. & map_view & Untuk menampilkan gambar maps pada layar \\
\hline
\end{tabular}


4.2 Implementasi Alur Program

4.2.1 Tampilan Opening

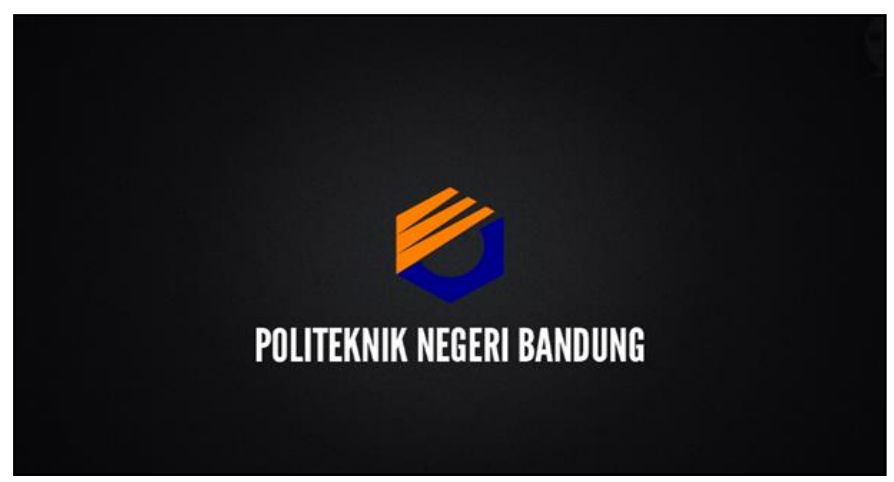

4.2.2 Tampilan Loading

Gambar 1. Tampilan Opening

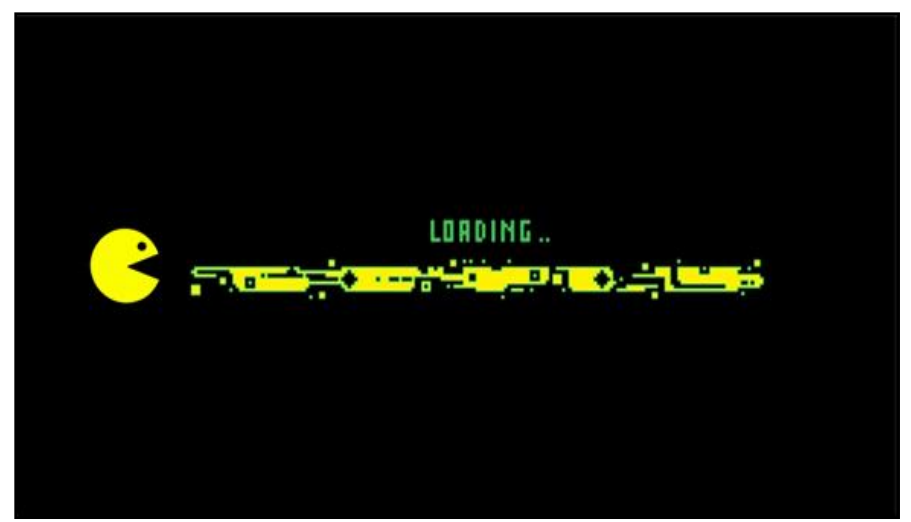

Gambar 2. Tampilan Loading

\subsubsection{Main Menu}

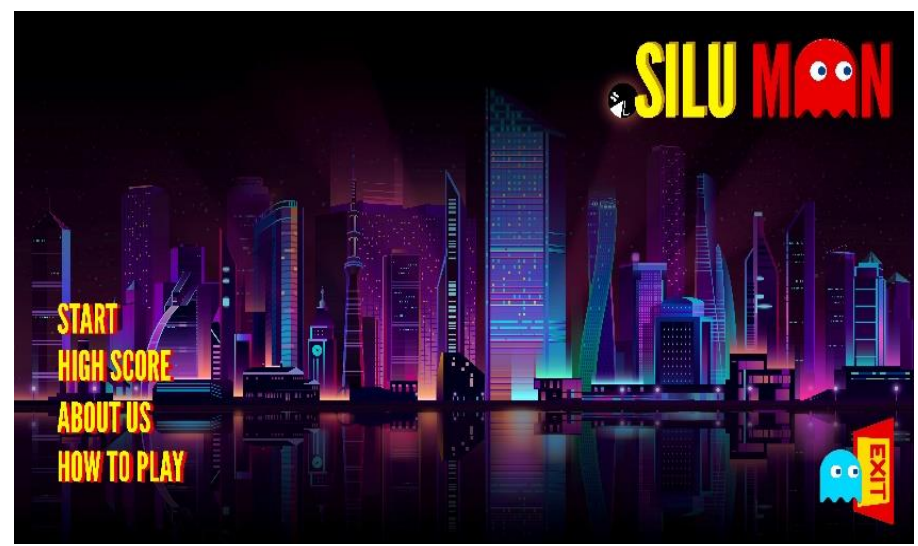

Gambar 3. Tampilan Opening 


\subsubsection{Aturan Permainan}

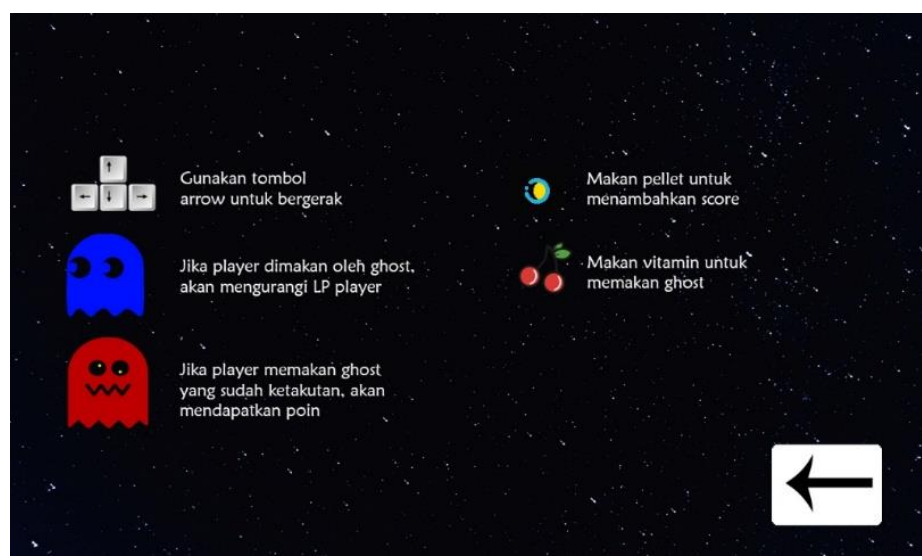

4.2.5 Profil Kelompok

Gambar 4. Tampilan Aturan Permainan

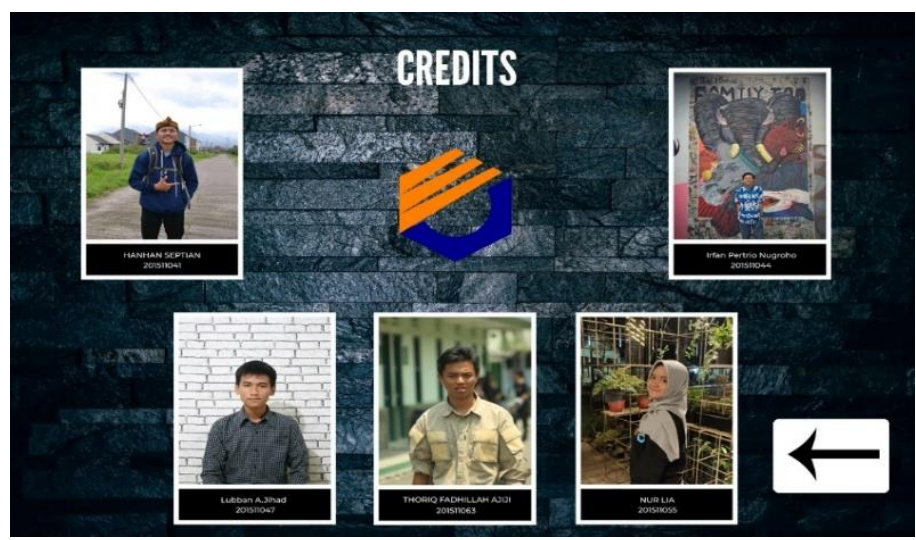

Gambar 5. Tampilan Profil Kelompok

\subsubsection{Tampilan highscore}

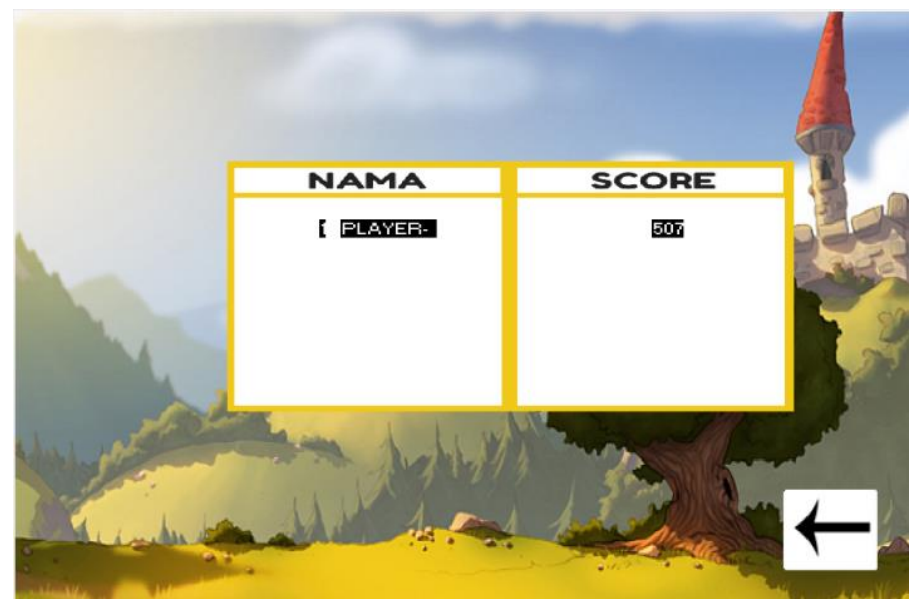

Gambar 6. Tampilan Highscore

Implementasi Struktur Data Tree Pada Game Pacman Dengan C(Hanhan Septian, Ida Suhartini, Irfan Pertrio N, Lubban Ahsanul Jihad, Nur Lia, Toriq Fadilah A) 


\subsubsection{Tampilan game}

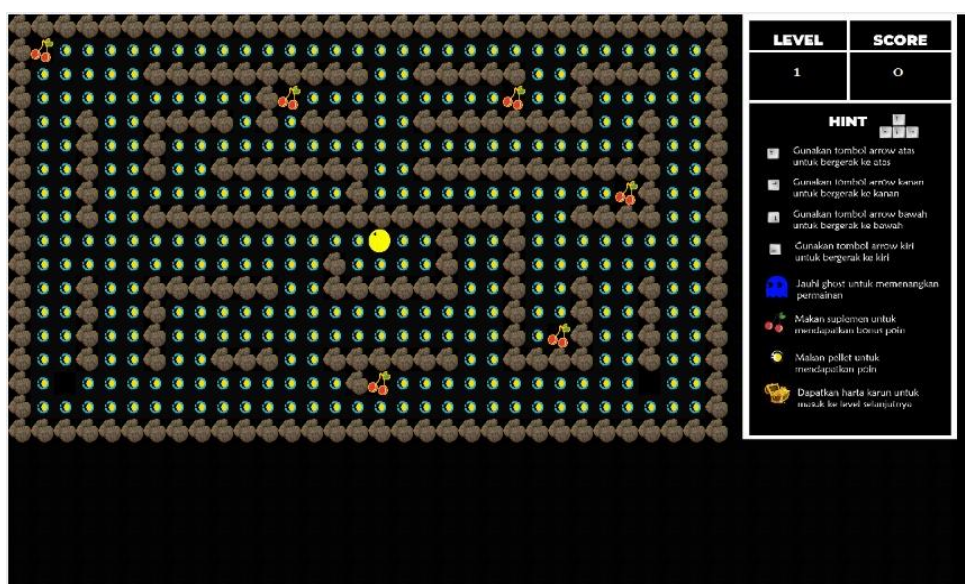

Gambar 7. Tampilan Game

4.2.8 Tampilan Game Over

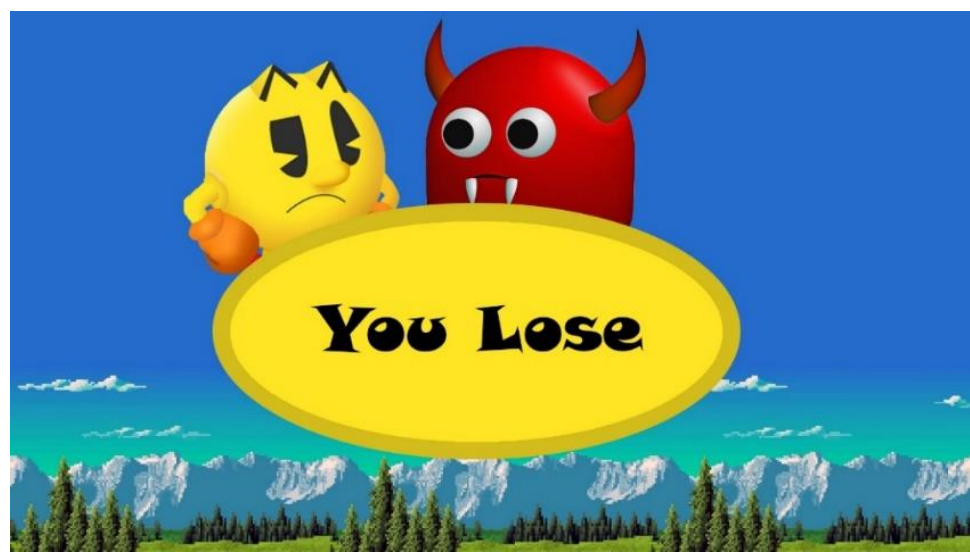

Gambar 8. Tampilan Game Over

4.2.9 Tampilan win

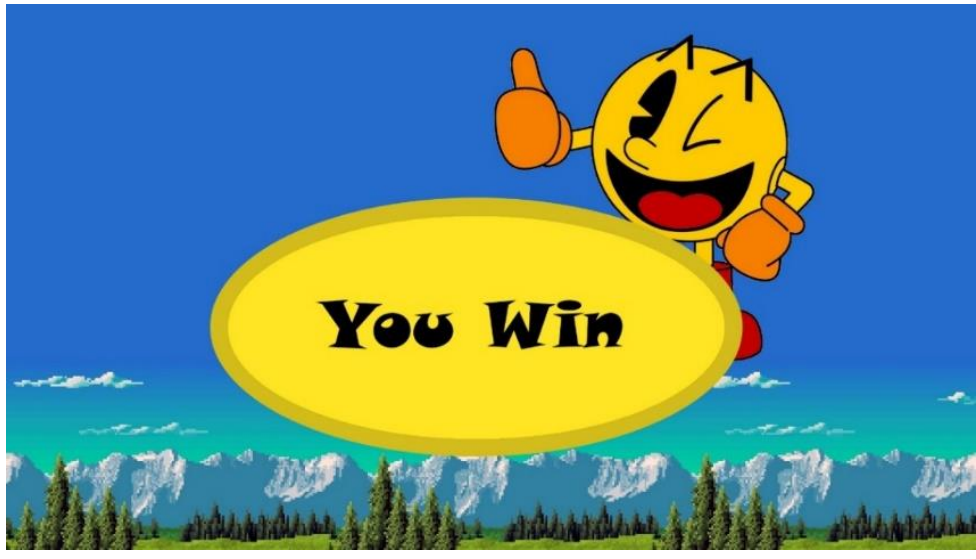

Gambar 9. Tampilan Game Over 


\subsubsection{Karakter}

1. Pac-Man

a. Pacman ke atas
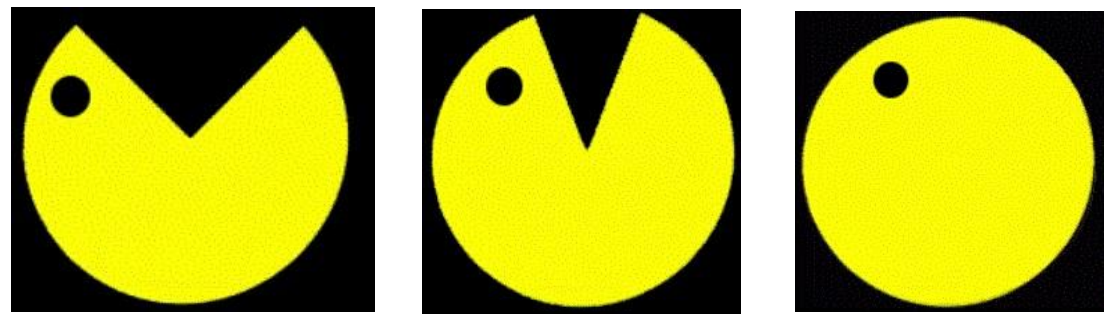

Gambar 10. Tampilan Pac-Man ke atas

b. Pacman ke bawah
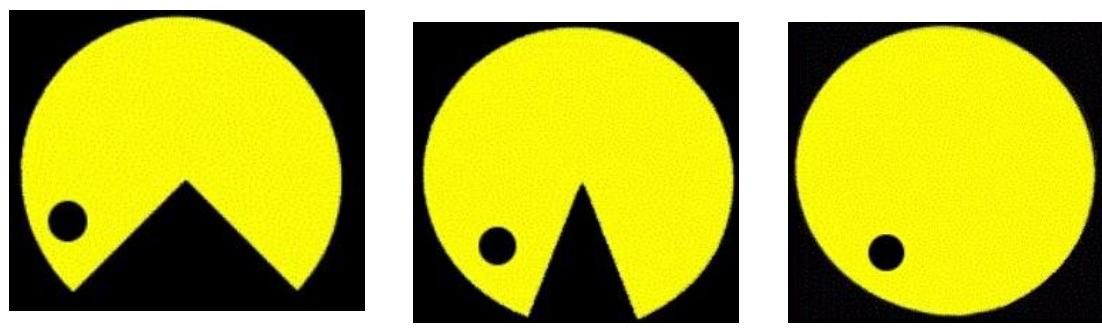

Gambar 11. Tampilan Pac-Man ke bawah

c. Pacman ke kanan
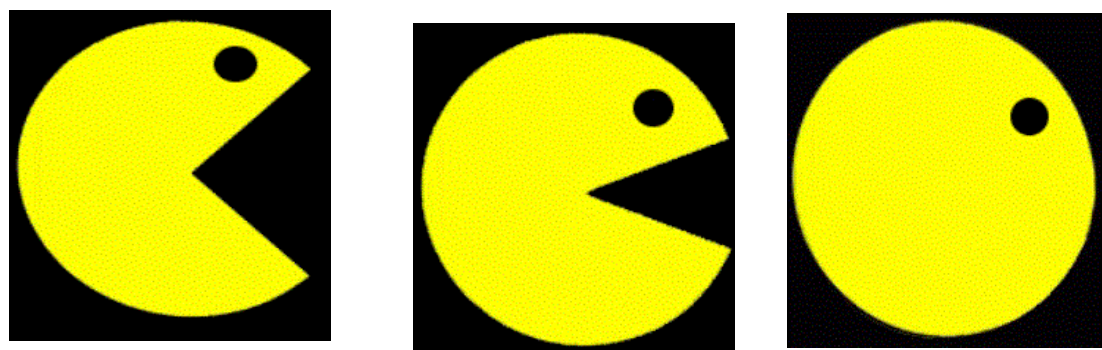

Gambar 12. Tampilan Pac-Man ke kanan

d. Pacman ke kiri
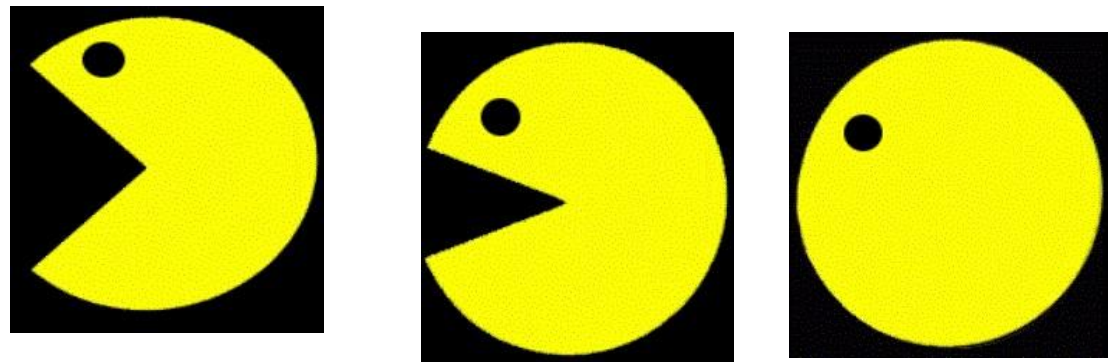

Gambar 13. Tampilan Pac-Man ke kiri 
2. Hantu

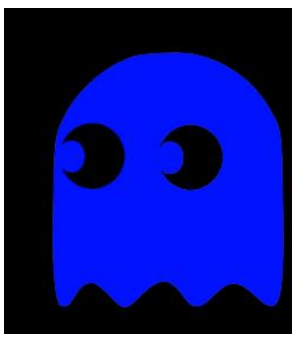

Gambar 14. Tampilan Hantu

3. Maps
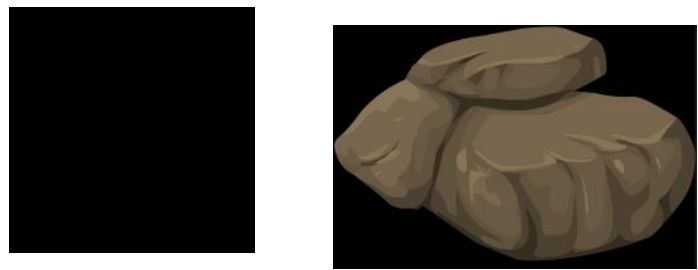

Gambar 15. Tampilan Maps

4. Pelet

Gambar 16. Tampilan Pelet

5. Gerbang

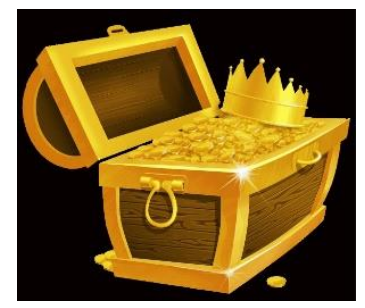

Gambar 17. Tampilan Gerbang 
6. Rules

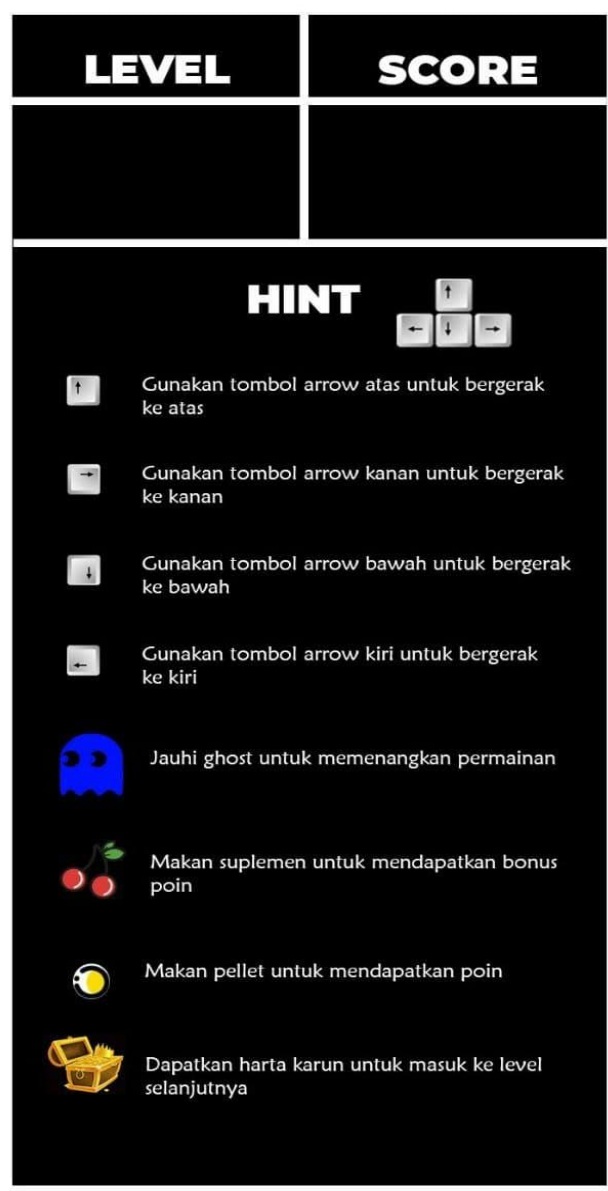

Gambar 18. Tampilan Rules Permainan

\section{KESIMPULAN}

Tujuan dibuatnya dari game Pac-Man ini ialah untuk menduplikasi dan juga membuat kembali permainan dengan struktur dan pemrograman C. Penerapan struktur data Tree pada perancangan, dapat menghasilkan karakter dan juga bentuk permainan yang sama dengan permainan sebelumnya. Walaupun masih ada keterbatasan, namun dari hasil implementasinya dapat menampilkan permainan Pac-Man seperti permainan aslinya.

\section{DAFTAR PUSTAKA}

[1] RINI WONGSO, S. 2017, March 15. School of Computer Science. Single Linked List. https://socs.binus.ac.id/2017/03/15/single-linked-list/

[2] Wikipedia.org. 2011, March 15.Kontributor dari proyek Wikimedia. layanan pesan singkat mobile dan media sosial yang dimiliki Facebook

[3] https://id.wikipedia.org/wiki/WhatsApp 
[4] Wikipedia.org. 2011, December 11.Kontributor dari proyek Wikimedia. layanan hos untuk proyek perangkat lunak yang menggunakan Git..

[5] https://id.wikipedia.org/wiki/GitHub

[6] Jefri Yonata. 2021, April 19.Panduan Lengkap Cara Menggunakan Google Meet di Semua Perangkat. Blog Dewaweb.

[7] https://www.dewaweb.com/blog/cara-pakai-google-meet/

[8] Wikipedia.org. 2014,January 10. Kontributor dari proyek Wikimedia. Code::Blocks. https://id.wikipedia.org/wiki/Code::Blocks

[9] Wikipedia.org. 2007, September 27. Kontributor dari proyek Wikimedia. Adobe Photoshop.

[10] https://id.wikipedia.org/wiki/Adobe_Photoshop

[11] MALIKI EDULOGI NUSANTARA. 2020, January 6. Pengenalan DEV-C++

[12] https://maliki.id/pengenalan-dev-c/

[13] rizkidoank .2016, October 17. Double Linked List.

[14] https://www.rizkidoank.com/2016/10/17/double-linked-list/

[15] GeeksforGeeks.2020, April 16. Construct a Doubly linked linked list from 2D Matrix https://www.geeksforgeeks.org/construct-a-doubly-linked-linked-list-from-2d-matrix/

[16] Modul Perkuliahan “ Struktur Data”, Ade Chandra 